\title{
Triethylamine and TBD supported on silica: useful heterogeneous catalysts for the reaction of $\beta$-dicarbonyl derivatives with $\alpha, \beta$-unsaturated compounds under batch and continuous flow conditions
}

\author{
Raimondo Maggi,* Calogero G. Piscopo, and Giovanni Maestri \\ “Clean Synthetic Methodology Group”, Dipartimento di Chimica dell'Università \\ Parco Area delle Scienze 17A, I-43124 Parma, Italy \\ E-mail: raimondo.maggi@unipr.it
}

Dedicated to Professor Manfred Schlosser in honor of his scientific achievements

DOI: http://dx.doi.org/10.3998/ark.5550190.p009.025

\begin{abstract}
The synthesis of either mono- or bis-adducts via Michael reaction between active methylene compounds and $\alpha, \beta$-unsaturated reagents is reported. These processes are catalyzed by two heterogeneous basic catalysts, namely $\mathrm{KG}^{-\mathrm{NEt}_{2}}$ and $\mathrm{KG}-\mathrm{TBD}$. Both catalysts show good catalytic efficiency and can be reused several times fully preserving their efficiency. The process could be efficiently performed under continuous flow conditions obtaining promising results in term of yield and selectivity.
\end{abstract}

Keywords: Heterogeneous catalysis, basic catalysts, Michael reaction, continuous flow procedure

\section{Introduction}

The search for new, efficient and low-cost catalysts for organic transformation represents a basic area of research. ${ }^{1-3}$ In this context heterogeneous catalysts are gaining importance as they represent a smart tool to carry out environmentally acceptable organic processes. While solid catalysts are mainly exploited in petrochemical and bulk chemistry transformations, ${ }^{4-5}$ there has been a great effort in the last decades to accomplish the synthesis of fine chemicals by means of heterogeneous catalysis.

As part of our ongoing interest in the preparation, characterization and use of catalysts supported on solid materials, ${ }^{6-9}$ we have synthesized two silica-supported organic bases, namely 
triethylamine and 1,5,7-triazabicyclo[4.4.0]dec-5-ene (TBD), to study their behavior in heterogeneous catalyzed reactions. These bases are routinely used as homogeneous catalysts to promote Michael reactions between active methylene compounds and $\alpha, \beta$-unsaturated reagents. This reaction represents indeed one of the most efficient methods for $\mathrm{C}-\mathrm{C}$ bond formation and its wide application in organic synthesis is well documented. ${ }^{10}$ These reactions are usually performed in the presence of strong bases (i.e. alkali metal alkoxides and hydroxides), ${ }^{11}$ transition metal complexes, ${ }^{12}$ solid acids (i.e. alumina and clays), ${ }^{13-15}$ and Lewis acids (i.e. $\mathrm{SnCl}_{4}$, $\mathrm{TiCl}_{4}$ and $\left.\mathrm{ZrCl}_{4}\right){ }^{16-18}$ More recently, TBD, ${ }^{19}$ silica-supported organic bases, ${ }^{20}$ enzymes ${ }^{21}$ and microsized cerium chloride ${ }^{22}$ have been used to efficiently catalyze these reactions.

\section{Results and Discussion}

We report herein the preparation of two different organic bases anchored on silica gel (KG-NEt 2 and KG-TBD - Figure 1) pivoting on literature procedures ${ }^{23-24}$ and their use as catalysts in the reaction between an $\alpha, \beta$-unsaturated compound and an active methylene reagent. Remarkably, it is possible to steer the selectivity towards either mono-alkylated products $\mathbf{3}$ or bis-alkylated adducts 4 depending on the strength of the basic catalyst (Scheme 1).

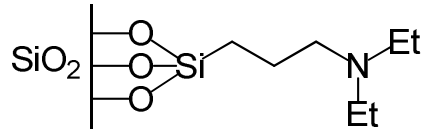

KG-NEt 2

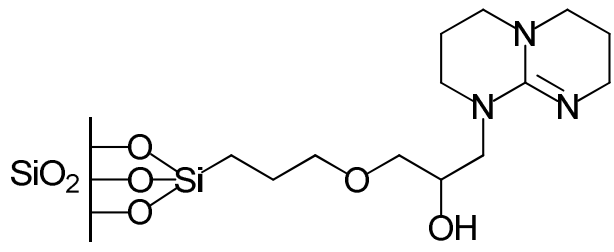

KG-TBD

Figure 1. $\mathrm{KG}^{-\mathrm{NEt}_{2}}$ and $\mathrm{KG}-\mathrm{TBD}$ structures.<smiles>[R]C(=O)CC([R])C([R])C([R])=O</smiles><smiles>[R]C=CC([R])=O</smiles>

Scheme 1. Mono- and bis-adducts obtained by reacting active methylene compounds and $\alpha, \beta$-unsaturated reagents.

These reactions were also performed in a continuous flow reactor. This strategy offers significant improvements compared to conventional batch processes due to a precise control of 
residence time, heat and mass transport, and is thus a route to minimize wastes and develop more efficient and sustainable syntheses. ${ }^{25}$

In a preliminary batch experiment, the model reaction of butenone $(\mathbf{1 a}-10 \mathrm{mmol})$ and pentane-2,4-dione (2a $-10 \mathrm{mmol})$ in toluene $(10 \mathrm{~mL})$ with $0.9 \mathrm{~g}$ of KG-NEt 2 (10\% mol - loading: $1.1 \mathrm{mmol} / \mathrm{g}$ ) has been carried out at room temperature. Upon 5 hours, the mono-alkylated Michael product 3aa was isolated in a poor yield (9\%) with high selectivity (100\%). In order to boost conversion of substrate seeking to maintain similarly high selectivity, reactions were carried out at higher temperatures. Results are summarized in Table 1.

Table 1. Influence of the temperature on both yield and selectivity in the reaction of butenone with pentane-2,4-dione (1/1 molar ratio)

\begin{tabular}{ccccc}
\hline Entry & $\mathrm{T}\left({ }^{\circ} \mathrm{C}\right)$ & 2a conversion $(\%)$ & 3aa yield $(\%)$ & 3aa selectivity $(\%)$ \\
\hline $\mathrm{a}$ & 25 & 9 & 9 & 100 \\
$\mathrm{~b}$ & 50 & 56 & 51 & 91 \\
$\mathrm{c}$ & 75 & 79 & 63 & 80 \\
$\mathrm{~d}$ & 100 & 97 & 70 & 72 \\
\hline
\end{tabular}

By carrying out the reaction at $50{ }^{\circ} \mathrm{C}$ a remarkable increase of the yield was observed $(51 \%$, entry b) together with a good level of selectivity (91\%). On the contrary, reactions carried out at higher temperatures showed slightly better yields with concomitant loss of selectivity (entries c and d).

We next investigated the amount of catalyst (Table 2).

Table 2. Influence of the catalyst amount on both yield and selectivity in the reaction of butenone and pentane-2,4-dione (1/1 molar ratio)

\begin{tabular}{ccccc}
\hline Entry & Catalyst $(\mathrm{mol} \%)$ & 2a conversion $(\%)$ & 3aa yield $(\%)$ & 3aa selectivity $(\%)$ \\
\hline a & 10 & 56 & 51 & 91 \\
b & 5 & 55 & 50 & 91 \\
c & 2.5 & 32 & 30 & 94 \\
\hline
\end{tabular}

Gratifyingly, the same yield value together with an high level of selectivity was observed by halving the catalyst amount (51\% and $91 \%$ respectively, entry a); reducing further the amount of KG-NEt ${ }_{2}$ to $2.5 \mathrm{~mol} \%$ preserved the high selectivity but proved to be detrimental for the yield (30\%, entry c).

The influence of the solvent was then considered by testing acetonitrile, isopropanol and water in the model reaction. The reaction carried out in acetonitrile showed very low conversion $(15 \%)$, whereas the same yield value observed with toluene was found with the other two more polar solvents (52 and 50\% using isopropanol and water respectively). In these two cases however selectivity dropped to lower levels ( 84 and $70 \%$ respectively). 
With best conditions in our hands (catalyst: $5 \%$ mol, 5 hours, $50{ }^{\circ} \mathrm{C}$, toluene), we have then investigated the recycling of the heterogeneous catalyst (Table 3).

Table 3. Catalyst recycle

\begin{tabular}{ccccc}
\hline Entry & Run & 2a conversion $(\%)$ & 3aa yield $(\%)$ & 3aa selectivity $(\%)$ \\
\hline a & 1 & 55 & 50 & 91 \\
b & 2 & 54 & 48 & 89 \\
c & 3 & 53 & 47 & 89 \\
d & 4 & 54 & 49 & 91 \\
e & 5 & 54 & 48 & 89 \\
\hline
\end{tabular}

At the end of each reaction, the KG-NEt 2 catalyst has been recovered by filtration and reused for the next run upon a simple toluene washing $(10 \mathrm{~mL})$. We were pleased that the catalyst efficiency in terms of yield and selectivity remains fully preserved for the first five cycles. We then unambiguously confirmed that the catalyst is a heterogeneous species by applying the well known "hot filtration test". 26

The second aim of the project has been to identify a suitable combination of catalyst and reaction conditions to selectively obtain bis-alkylated products 4 . Even by increasing the reaction time, the reaction temperature and the butanone/pentane-2,4-dione ratio it was not possible however to achieve good yield and selectivity of the target compound with the KG-NEt 2 catalyst. We ascribed this lack of reactivity to the low basicity of the catalyst; consequently we decided to prepare an heterogeneous catalyst, as KG-TBD, bearing a stronger base to perform this process. An encouraging result was achieved by carrying out the reaction in toluene for 5 hours at room temperature with $5 \mathrm{~mol} \%$ of the catalyst with the tethered guanidine moiety (loading: 0.6 $\mathrm{mmol} / \mathrm{g}$ ) and with a 3/1 molar ratio of butenone/pentane-2,4-dione. We were then delighted to recover bis-adduct 4aa in $91 \%$ yield and to observe almost complete selectivity towards this product $(97 \%)$. On the contrary, by carrying out the reaction with a lower reagent ratio, a decrease in both yield and selectivity were observed.

We have then evaluated the influence of the catalyst amount on the efficiency of the process and results are reported in Table 4.

Table 4. Influence of the catalyst amount on both yield and selectivity in the reaction between butenone pentan-2,4-dione (3/1 molar ratio)

\begin{tabular}{ccccc}
\hline Entry & Catalyst $($ mol \%) & 2a conversion $(\%)$ & 4aa yield $(\%)$ & 4aa selectivity $(\%)$ \\
\hline a & 10 & 100 & 84 & 84 \\
b & 5 & 94 & 91 & 97 \\
c & 2.5 & 86 & 85 & 99 \\
\hline
\end{tabular}


From the data reported we can conclude that by halving the catalyst amount ( $2.5 \mathrm{~mol} \%$, entry c) a lower yield was observed but the same very high selectivity was preserved; on the contrary, by doubling the KG-TBD amount, full conversion of pentane-2,4-dione was registered but both yield and selectivity were reduced ( $84 \%$ each, entry a). This behavior could be ascribed to the formation of cyclized products (not identified) due to intramolecular aldol condensation (Figure 2).

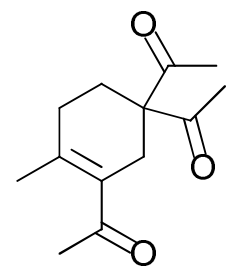<smiles>CC(=O)CCC1(C(C)=O)CCC(C)=CC1=O</smiles>

Figure 2. Possible by-products derived from intramolecular aldol condensation of 4aa adduct.

With the two complementary methodologies to obtain either mono- or bis-adduct products using the same reagents by simply switching the heterogeneous catalysts and the molar ratio of substrates, we have then conceived to perform the reaction under continuous flow conditions.

For continuous flow experiments a simple process was set up using two empty HPLC columns $(6.0 \mathrm{~cm}$ length $\times 0.8 \mathrm{~cm}$ inner diameter $)$ packed with the two catalysts. Two pulsationfree syringe pumps were connected to the reactor allowing a precise control of the flow rate of the solution of each reagent; the two columns were placed in a GC oven in order to carefully control heating (Figure 3).

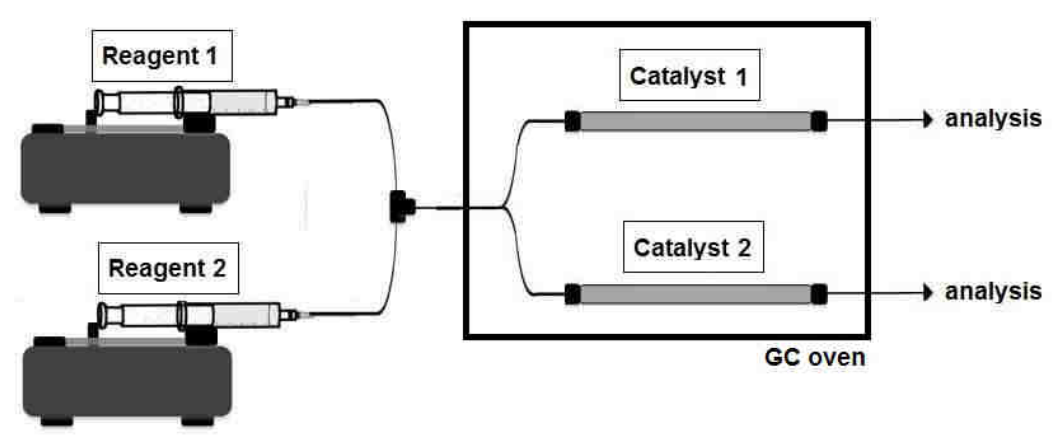

Figure 3. Schematic diagram of the reactor setup for the continuous flow process.

By carrying out the model reaction between butenone and pentan-2,4-dione (1:1 molar ratio) with $\mathrm{KG}-\mathrm{NEt}_{2}$ catalyst in toluene at $50{ }^{\circ} \mathrm{C}$ with a residence time of 15 minutes, product 3aa was obtained in $20 \%$ yield with a selectivity value of $93 \%$. Pivoting on this result, the reaction was further investigated through a systematic variation of key parameters such as temperature and residence time. The best result was achieved by performing the reaction at $50{ }^{\circ} \mathrm{C}$ and increasing 
the residence time to 50 minutes tuning flow rates; the yield raised to $55 \%$ and a good level of selectivity was preserved (92\%).

The best conditions to synthesize bis-alkylated product 4 aa were found flowing at room temperature butenone and pentane-2,4-dione in a 3:1 molar ratio through the column fitted with KG-TBD catalyst with a residence time of 40 minutes. Using this continuous flow process 4 aa was formed with $93 \%$ yield and $98 \%$ selectivity.

Finally we investigated the scope of the reaction under continuous flow conditions (Table 5).

Table 5. Preparation of various mono- and bis-adducts derived from the reaction between active methylene compounds and $\alpha, \beta$-unsaturated reagents

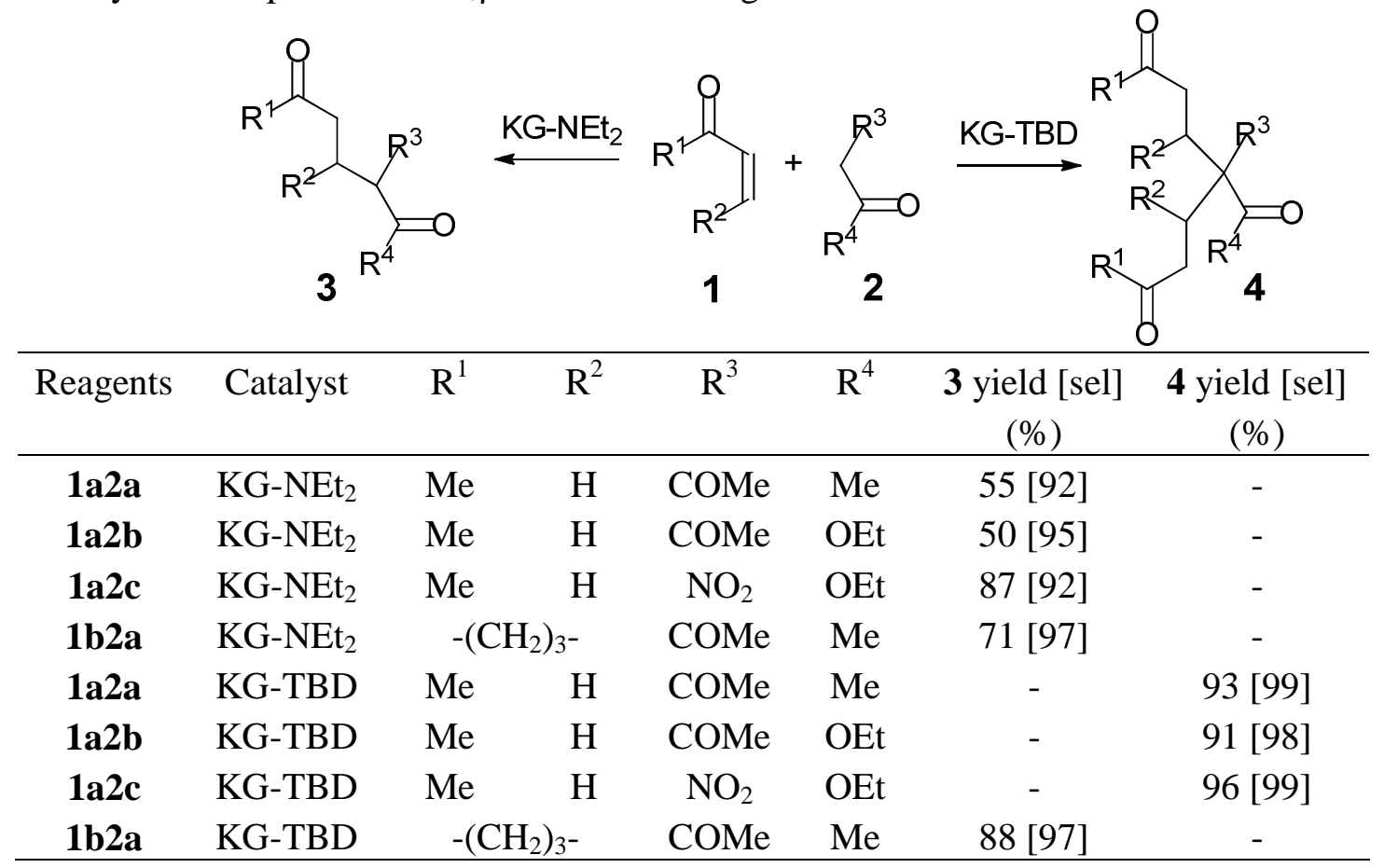

The results of Table 5 show that the mono-addition of active methylene compounds and $\alpha, \beta$-unsaturated reagents can be accomplished with good yields (50-87\%) and selectivities

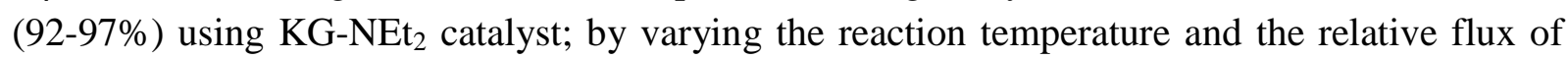
reagents it is possible to synthesize bis-adduct products $\mathbf{4}$ simply switching the desired catalyst column with very high yields (91-96\%) and excellent selectivities. It is worth noting that 2-cyclohexenone delivers selectively mono-adduct product $\mathbf{3}$ only using both catalysts; the second addition of a 2-cyclohexenone molecule on the mono-addition product do not occur probably owing to the increased steric hindrance. 


\section{Conclusions}

We reported that $\mathrm{KG}-\mathrm{NEt}_{2}$ and $\mathrm{KG}-\mathrm{TBD}$ heterogeneous materials can be employed as catalysts with tunable basic strength to synthesize either mono- or bis-adduct products via Michael reaction of active methylene compounds and $\alpha, \beta$-unsaturated reagents by slightly modifying reaction conditions. Remarkably, both processes can be carried out under continuous flow conditions simply by switching the feeding of reagents to the column with the desired catalyst. Through this approach it is possible to alternatively synthesize either mono- or bis-adduct products with very high yields and excellent selectivities by varying residence time and molar ratio of reagents.

\section{Experimental Section}

General. All the reagents and solvents were purchased from Aldrich and used without further purification. Amorphous silica used to prepare catalysts was purchased from Merck (Kieselgel 60, KG-60); prior to functionalization, the siliceous supports were dried at $300{ }^{\circ} \mathrm{C}$ for 15 hours. Elemental analyses to determine catalyst loading were performed using a Carlo Erba CHNS-0 EA1108 Elemental Analyzer. Gas-chromatographic analyses were accomplished on a TraceGC ThermoFinnigan instrument (FID).

KG-NEt 2 $N, N$-diethyl-3-aminopropyltrimethoxysilane $(12.7 \mathrm{mmol}, 3.0 \mathrm{~g}, 3.2 \mathrm{~mL})$ was added to a suspension of previously dried KG-60 silica $(3 \mathrm{~g})$ in refluxing toluene $(50 \mathrm{~mL})$ and the mixture was kept under stirring for $1.5 \mathrm{~h}$ at the same temperature. Toluene and formed methanol were removed and the resulting solid was then poured again into refluxing toluene $(50 \mathrm{~mL})$ for 1.5 hours. This sequence was repeated two times. The modified solid was filtered, washed in a Soxhlet apparatus with diethyl ether $(20 \mathrm{~mL})$ and dichloromethane $(20 \mathrm{~mL})$ and eventually dried at $110^{\circ} \mathrm{C}$.

KG-TBD. TBD (87.2 mmol, 1 g) was added to a solution of 3-trimethoxysilylpropoxymethyloxirane $(5.9 \mathrm{mmol}, 1.3 \mathrm{~mL})$ in dry DMF $(10 \mathrm{~mL})$ and the mixture was kept under stirring for $15 \mathrm{~h}$ at $\mathrm{rt}$. The solution was then poured into a flask containing dry toluene $(50 \mathrm{~mL})$ and previously dried KG-60 silica $(3.5 \mathrm{~g})$. The resulting slurry was refluxed for $1 \mathrm{~h}$ and then methanol and toluene were distilled out. This operation was repeated 3 times. The resulting solid was then filtered, washed with toluene $(20 \mathrm{~mL})$, methylene chloride $(20 \mathrm{~mL})$ and methanol $(20 \mathrm{~mL})$ and eventually treated for $24 \mathrm{~h}$ in a Soxhlet apparatus using a 1/1 diethyl ether/methylene chloride mixture to afford the desired heterogeneous catalyst upon $2 \mathrm{~h}$ of vacuum drying.

Catalytic reactions under batch conditions. In a stirred batch reactor equipped with a condenser and a thermometer, toluene $(10 \mathrm{~mL})$, the selected active methylene compound (10 $\mathrm{mmol}$ ), the desired $\alpha, \beta$-unsaturated reagent (10 mmol to synthesize compounds $\mathbf{3}$ or $30 \mathrm{mmol}$ for 
the synthesis of products 4$)$ and the heterogeneous catalyst $\left(0.9 \mathrm{~g}\right.$ of $\mathrm{KG}^{-\mathrm{NEt}_{2}}$ for the synthesis of $\mathbf{3}$ or $0.8 \mathrm{~g}$ of KG-TBD for products 4 ) were stirred at either $50{ }^{\circ} \mathrm{C}$ (for compounds 3 ) or at $\mathrm{rt}$ (for the synthesis of products 4 ) for 5 hours. Then the solid catalyst was recovered by filtration and the reaction mixture was analyzed by high resolution capillary GC with a fused silica capillary column SPB-20 from Supelco $(30 \mathrm{~m}$ x $0.25 \mathrm{~mm}$ ) using decane as internal standard. The products were identified by comparing their spectral data with those reported in the literature..$^{22,27-31}$

Catalytic reactions under continuous flow conditions. A steel HPLC column $(6.0 \mathrm{~cm}$ length $\mathrm{x}$

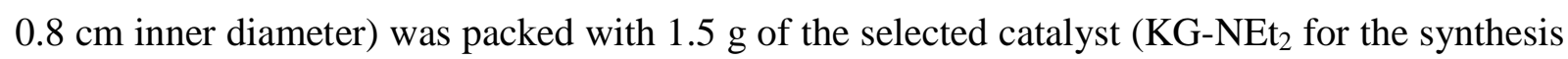
of compounds 3 and KG-TBD for the synthesis of compounds 4). Two pulsation-free syringe pumps were connected to the reactor allowing a precise control of the flow rate of the toluene solution $(0.9 \mathrm{~mol} / \mathrm{l})$ of both reagents. The reagents were passed through the reactor in stoichiometric ratio for the synthesis of compounds 3 and in a 3/1 ratio for the synthesis of compounds 4 . Total residence time was 50 and $40 \mathrm{~min}$ respectively. The eluates were analyzed by high resolution capillary GC with a fused silica capillary column SPB-20 from Supelco (30 m $\mathrm{x} 0.25 \mathrm{~mm}$ ) using decane as internal standard.

\section{References}

1. Corma, A. Chem. Rev. 1995, 95, 559. http://dx.doi.org/10.1021/cr00035a006

2. Clark, J. H.; Macquarrie, D. J. Chem. Soc. Rev. 1996, 303. http://dx.doi.org/10.1039/cs9962500303

3. Sheldon, R. A. Chem. Ind. (London) 1997, 12.

4. Perego, C. ; Carati, A. in Zeolites: From Model Materials to Industrial Catalysts; Čejka, J.; Peréz-Pariente, J. ; Roth, W. J. Eds.; Transworld Research Network: Kerala, 2008; p. 357.

5. Emam, E. A. ARPN J. Sci. Technol. 2013, 3, 356.

6. Ballini, R.; Bigi, F.; Gogni, E.; Maggi, R.; Sartori, G. J. Catal. 2000, 191(2), 348. http://dx.doi.org/10.1006/jcat.1999.2759

7. Sartori, G.; Armstrong, A.; Maggi, R.; Mazzacani, A.; Sartorio, R.; Bigi, F.; DominguezFernandez, B. J. Org. Chem. 2003, 68, 3232. http://dx.doi.org/10.1021/jo034044c

8. Gregori, F.; Nobili, I.; Bigi, F.; Maggi, R.; Predieri, G.; Sartori, G. J. Mol. Catal. A: Chem. 2008, 286, 124. http://dx.doi.org/10.1016/j.molcata.2008.02.004

9. Maggi, R.; Chitsaz, S.; Loebbecke, S.; Piscopo, C. G.; Sartori, G.; Schwarzer, M. Green Chem. 2011, 13, 1121. http://dx.doi.org/10.1039/c0gc00887g 
10. Jung, M. E. in Comprehensive Organic Synthesis; Trost, B. M.; Fleming, I. Eds.; Pergamon: Oxford, 1991, 1. http://dx.doi.org/10.1016/B978-0-08-052349-1.00090-1

11. Bergmann, E. D.; Ginsburg, D.; Pappo, R. Org. React. 1953, 10, 179.

12. Christoffers, J. Eur. J. Org. Chem. 1998, 1259. http://dx.doi.org/10.1002/(SICI)1099-0690(199807)1998:7<1259::AIDEJOC1259>3.0.CO;2-J

13. Soriente, A.; Arienzo, R.; Rosa, M. D.; Palombi, L.; Spinella, A.; Scettri A. Green Chem. 1999, $1,157$. http://dx.doi.org/10.1039/a902102g

14. Boruah, A.; Baruah, M.; Prajapati. D.; Sandhu, J. S. Chem. Lett. 1996, 965.

15. Ranu, B. C.; Bhar, S. Tetrahedron Lett. 1992, 48, 1327. http://dx.doi.org/10.1016/S0040-4020(01)90794-X

16. Rele, D. N; Trivedi, G. K. J. Sci. End. Res. 1993, 52, 13.

17. Nelson, J. H.; Howells, P. N.; De Lullo, G. C.; Landen, G. L.; Henry, R. A. J. Org. Chem. 1980, 45, 1246.

http://dx.doi.org/10.1021/jo01295a017

18. Smitha, G.; Patnaik, S.; Reddy, C. S. Synthesis 2005, 711.

19. Ye, W.; Xu, J.; Tan, C.-T.; Tan, C.-H. Tetrahedron Lett. 2005, 46, 6875. http://dx.doi.org/10.1016/j.tetlet.2005.08.010

20. Ballini, R.; Bosica, G.; Livi, D.; Palmieri, A.; Maggi, R.; Sartori. G. Tetrahedron Lett. 2003, 44, 2271. http://dx.doi.org/10.1016/S0040-4039(03)00274-0

21. Xu, J.-M.; Zhang, F.; Wu, Q.; Zhang, Q.-Y.; Lin, X.-F. J. Mol. Catal. B: Enzym. 2007, 49, 50. http://dx.doi.org/10.1016/j.molcatb.2007.08.004

22. Terent'ev, A. O.; Vil', V. A.; Yaremenko, I. A.; Bityukov, O. V.; Levitsky, D. O.; Chernyshev, V. V.; Nikishin, G. I.; Fleury, F. New J. Chem. 2014, 38, 1493. http://dx.doi.org/10.1039/c3nj01454a

23. Cauvel, A.; Renard, G.; Brunel, D. J. Org. Chem. 1997, 62, 749. http://dx.doi.org/10.1021/jo9614001

24. Subba Rao, Y. V.; De Vos, D. E.; Jacobs, P. A. Angew. Chem., Int. Ed. Engl. 1997, 36, 2661. http://dx.doi.org/10.1021/j09614001

25. Mason, B. P.; Price, K. E.; Steinbacher, J. L.; Bogdan, A. R.; McQuade, D. T. Chem. Rev. 2007, 107, 2300 . http://dx.doi.org/10.1021/cr050944c

26. Lempers, H. E. B.; Sheldon, R. A. J. Catal. 1998, 175, 62. http://dx.doi.org/10.1006/jcat.1998.1979

27. Noda, H.; Motokura, K.; Miyaji, A.; Baba, T. Adv. Synth. Catal. 2013, 355, 973. http://dx.doi.org/10.1002/adsc.201300063 
28. Guideri, L.; De Sarlo, F.; Machetti, F. Chem. Eur. J. 2013, 19, 665. http://dx.doi.org/10.1002/chem.201202698

29. Campana, A. G.; Fuentes, N.; Gomez-Bengoa, E.; Mateo, C.; Oltra, J. E.; Echavarren, A. M.; Cuerva, J. M. J. Org. Chem. 2007, 72, 8127. http://dx.doi.org/10.1021/jo701354c

30. Banerjee, S.; Santra, S. Tetrahedron Lett. 2009, 50, 2037. http://dx.doi.org/10.1016/j.tetlet.2009.01.154

31. Picquet, M.; Bruneau, C.; Dixneuf, P. H. Tetrahedron 1999, 55, 3937. http://dx.doi.org/10.1016/S0040-4020(99)00115-5 